\title{
Supporting Capacity Building in Health Service Provision in Eritrea via Distance Learning Master's Programmes: The Challenges and Rewards
}

Dr Joanne Corlett and Dr Linda Martindale University of Dundee

\begin{abstract}
A qualitative study investigating the experiences and effects on practice of Eritrean healthcare professionals studying for a postgraduate degree by distance learning is reported. The programme is delivered via online learning together with in-country teaching visits. Two focus group discussions with 19 postgraduate students were conducted. Online learning is challenging due to intermittent connectivity and power cuts, but students have developed their own solutions to overcoming these difficulties. Thematic analysis generated four themes. Students who are embedded within the Eritrean context are experiencing a process of self-development, both academic and personal. This self-growth is facilitating the development of resilience and confidence building, enabling students to have a positive influence on health service provision, thus impacting on the Eritrean context. Students are developing life-long skills that will support the continuing development of healthcare systems in Eritrea long after they have completed their distance learning programme.
\end{abstract}

Keywords: postgraduate, developing countries, Sub-Saharan Africa, healthcare education, blended learning

\section{Introduction}

\section{Eritrea: Background Context}

Eritrea, a Sub-Saharan country in the Horn of Africa, is a young nation, having gained formal independence in 1993 following a thirty year War of Independence with Ethiopia (World Bank, 2000). The conflict damaged the infrastructure of the country, including health services, which the Eritrean Government is reconstructing (UN, 2014). Substantial progress has been made towards achieving Millennium Development Goals, with significant reductions in infant, maternal, and under-five mortality; decreased rates of HIV, malaria, and TB infection; and a successful immunization 
programme (WHO, 2014). However, despite recent progress Eritrea remains one of the least developed countries of the world (World Bank, 2015). Malnutrition rates remain high and the burden of noncommunicable diseases such as diabetes, cardiovascular disease, and cancer are increasing (World Bank, 2015; WHO, 2014). As the health needs of the population change, professionals with the expertise and skill-set to respond to these are needed. A challenge for Eritrea is having appropriate numbers of highly skilled health professionals able to continue to drive high quality service development: "In spite of the remarkable progress in the development of human resources and achievement of health targets, the country is facing the challenge of insufficient skilled human resources to cope adequately with emerging and re-emerging health issues" (WHO, 2014, p.47).

Higher education provision has expanded following independence, but opportunities to undertake continuing professional education remain limited. The existing infrastructure is not able to fully meet the demand for capacity building, but distance learning via an overseas university offered a solution, providing opportunities for health professionals to further their education while applying new knowledge and skills directly to the practice arena. This type of in-country opportunity helps support capacity building and reduces the "brain drain" created by individuals having to study abroad (Shams \& Huisman, 2012, p.108).

\section{Partnership with the University of Dundee}

The University of Dundee has expertise in distance learning and in 2003 entered into partnership with the Eritrean Ministry of Health to support capacity building for health professionals, providing distance learning programmes for nurses and professionals working in the health sector. Since then more than 150 students have successfully gained a baccalaureate award. In 2013, the Ministry of Health and University agreed to further progress this capacity building, recruiting a cohort of 23 students to master's level distance learning programmes in global health and well-being, nursing, and mental health. Seven of these students had completed a top-up diploma to degree programme via distance learning with the University of Dundee, and the remaining 16 had completed a baccalaureate degree in Eritrea. The cohort is thus a mix of students who have completed traditional face to face programmes and those who had completed a face to face programme in Eritrea to diploma level, then completing to baccalaureate level (normally two years of part-time study) as a distance learner. These students have progressed to dissertation stage and are conducting research studies that will help inform health service development in Eritrea.

The programmes are delivered using a blended approach of online delivery together with in-country teaching visits twice per year, where each visit provides a week of face to face (f2f) teaching. A longitudinal case study has been gathering data on students' progression through the programme. This article reports on a specific element of the research, focusing on students' experiences of this type of delivery and the skills and knowledge they have developed.

\section{Programme Structure and Philosophy}

The programme is founded on Knowles' theory of andragogy (Knowles, 1990), underpinned by both an independent and collaborative learning pedagogy. Collaborative learning is based on the theory of social constructivism (Vygotsky, 1978) whereby learning is gained via active engagement with othersstudents, teachers, and learning content. Gravani \& Karagiori (2014) explain that although independent learning focuses on student-directed individual learning, while collaborative learning emphasizes learning acquired via social interaction with others, the two models can be complementary. This is the 
philosophy within the programmes evaluated here. Students are encouraged to engage in personal learning and to engage with others (students and teachers) to further enhance this.

Interaction is crucial to distance learning. Students need to interact with learning materials, each other, and the teaching team (Bernard et al. 2009). Promoting interaction online has its own challenges, which are accentuated where internet connectivity and power supplies are intermittent, as is the case in Eritrea. In-country teaching visits provide a means of overcoming these challenges. They occur before the start of an academic term, orienting students to their upcoming module. Back up data sticks containing the e-learning resources, reading materials, and core textbooks are distributed. Van Zyl, Els, and Blignaut (2013) note distance learning programmes often use supplementary faf sessions to enhance distance learning by providing additional opportunities for interaction. Ongoing learning is supported via the University's virtual learning platform as students progress through e-learning materials engaging in online activities with teachers and other students enrolled on the module.

\section{Research Objectives}

The study aimed to explore the experiences and effects on practice of Eritrean healthcare professionals studying for a postgraduate degree by distance learning.

\section{Methodology}

An exploratory qualitative case study approach was used to capture detailed textual data, the range of learning experiences and how these had influenced students' practice. The Eritrean case includes all 22 students in the class (one student left the programme during the first year). The students are all healthcare professionals working for the Ministry of Health; 15 students work in public health, the other seven are nurses. Students were recruited to the study during an in-country teaching visit. It was emphasised to students that the research study was independent of their teaching and study, to ensure that there was no coercion. Nineteen students gave written consent. Sixteen students were male, three were female. The age range of students was 30 to 60 and over.

The data was gathered using focus group discussions (FGDs). The FGD interview schedule was developed by the research team and consisted of seven open questions, focused on experiences of learning at master's level, including the effects of study on their own practice and practice setting. Focus groups were used to capture individual experiences and the consensus or variation within the group. The students having studied together for almost three years, are comfortable with participating in group discussion and debate, having taken part in workshops and group work throughout their studies. In such a group FGDs are well suited to capturing group opinions and reactions, as well as enabling individual contributions (Gerrish \& Lacey, 2010). Two FGDs, each lasting just over an hour, were held on consecutive days ( $\mathrm{n}=10$ and $\mathrm{n}=9$ ) and were recorded. The same seven questions were asked on each occasion with additional questions then used to explore students' comments in more detail. The interviews continued until the students had no further comments to make, at which point it was assumed saturation point had been achieved. They were facilitated by a member of the teaching team who is not part of the research study and a moderator took notes throughout the discussion. 
The FGDs were transcribed, requiring several intense reviews of the recordings. The students all have English as a second language so precise transcription was important to ensure words and meanings were captured accurately. The transcriptions were analyzed using a framework that was developed by members of the research team, using the research aims and FGD questions as guides. A qualitative thematic analysis was used, with data initially coded; themes were then identified, based on the framework.

Ethical approval for the study was granted by the University of Dundee and permission to carry out the FGDs was given by senior Ministry of Health officials in Eritrea.

\section{Results}

Thematic analysis of the focus groups generated four themes linked in a cyclical order, embedded against the backdrop of the programme which provides an underpinning theme as represented in Figure 1.

\section{The Programme}

Students are rooted within the Eritrean context. Undertaking the programme has resulted in selfdevelopment, confidence building, and the ability to influence others and have an impact, which in turn is affecting this Eritrean context. Students spoke about the specific skills they have developed since commencing the programme. They also discussed the advantages of being able to engage in distance, online learning, and the challenges they had faced.

Distance learning was new to most of the students, although seven students had already completed a baccalaureate top up programme with the University. However, online e-learning was a novel and innovative experience for all of them. Those who had previously studied with the University of Dundee had received learning materials in printed format. Students explained that both distance and e-learning was a very different approach to what they were used to and this had taken some adjustment. 


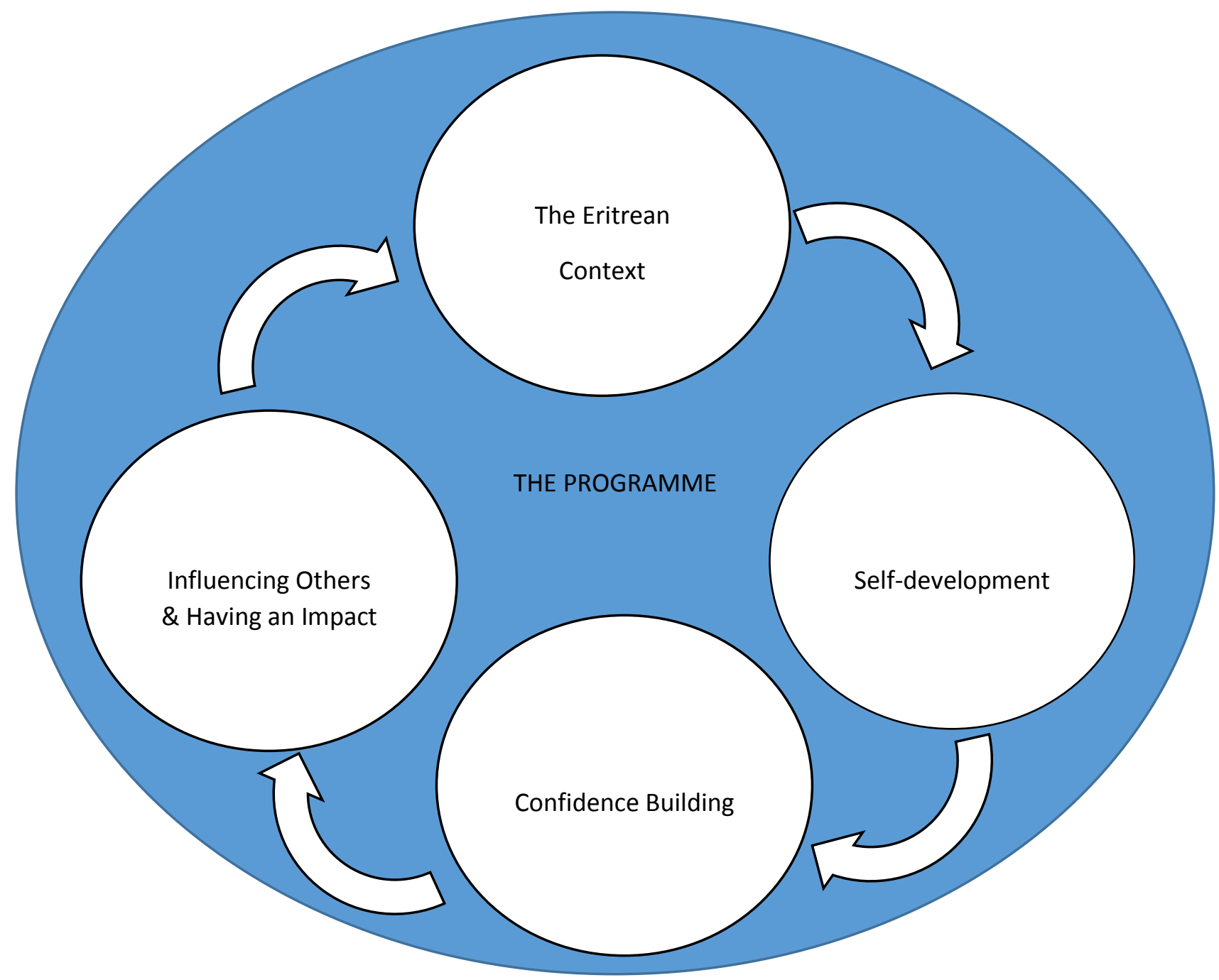

Figure 1. Conceptual model of emerging themes.

Student-centred, rather than teacher-centred learning was the main difference, adapting to being "guided" rather than "instructed" had required them to develop new ways of studying and learning. Students in general had embraced this change, recognising the advantages it provided, appreciating the flexibility of being able to fit their studies around work, social and family commitments - an important consideration for students in full-time employment, studying in their own time: "I have enjoyed this course, this masters programme because in a sense you are living in your country, your family, your loved ones while fulfilling all social obligations and acquiring new skills of masters, it's very very special."

One student expressed this as being given time to learn:

so you learn by yourself. . . you manage the time... instead of providing chunks of time, in the virtual one, time is given to you. . . as you learn by yourself. So that was one of the enjoyable things.

This fits with the student-centred, independent learning pedagogy underpinning the programme. However, students recognized they had to be disciplined in order to benefit from this flexibility, 
realising the importance of time management: "I manage my use of time, when to work when to do the social obligations, when to study, if you are O.K. with time, I think it is very manageable.... Discipline. .. if you didn't do that you can't study."

Another advantage was that studying part-time while continuing to work enabled them to apply their learning directly to their professional environment. Students gave examples of this: encouraging colleagues to be more critical and questioning in their practice; implementing changes in practice designed to be more patient/client focused; applying new research skills to projects they were leading. Students were keen to share their learning with others seeing this as a way of transforming practice, services and the Eritrean context. Applying learning immediately to the practice arena was a positive element compared to full time master's programmes that require students to disengage with practice while studying: "there is no time to share, to take forward other issues, for me they are not good awards. They are confined to their study."

Students appreciated opportunities to apply their new knowledge to practice and saw this as a ripple effect as they shared their knowledge with others. A confounding factor was the frustration of having set aside study time, only to find themselves unable to access the internet. Connectivity was a major challenge and is discussed more fully in section 2c, "Responding to challenges and resilience building." Despite these challenges, students were enjoying their studies, recognizing that their skills and knowledge were expanding. The in-country visits were identified as one of the most useful elements of the programme, as students relished the opportunity to engage directly with teaching staff and other students.

Against this backdrop of comments about the programme, four main themes emerged, linked to each other and shaped by the programme.

\section{Theme 1: The Eritrean Context}

The cycle begins and ends with the Eritrean context. Students spoke initially about the current situation in Eritrea. As a young nation in the aftermath of prolonged war, the country is still building its infrastructure. Students spoke about the thirst for learning that exists. However, opportunities are few: "In Eritrea there are limited universities, there is limited access to postgraduate. And second one most of the universities they don't give evening classes or part time classes."

The students recognized the need to develop individuals who would be able to contribute to capacity building, the lack of research specific to the Eritrean context, and the need to rectify this: "Plus there are many, many research questions waiting in the country. So many questions. . . there is no research conducted in this country that is a baseline."

Students believed master's level studies would equip individuals with the knowledge and skills to be able to engage in such research. The Ministry of Health leads and shapes the development of services and policy within the country. Students spoke of the need to ensure those working within the Ministry have the expertise to contribute effectively to project and policy development, recognising the importance of advanced education at master's and $\mathrm{PhD}$ level as a means of achieving this. They also discussed the need for Eritrea to play a role in influencing the wider strategic landscape across Africa: 
There is a gap, a clear gap... the people who are masters in $\mathrm{PhD}$ are very few... I think that is a very crucial issue because. ... the ministry it is strong, strong human resource that can develop the policy that can develop the strategy plans for Africa at the government's level.

Students felt they were part of this capacity building, stressing the importance of being able to contribute to their community and country: "What we have to do now is. . we have to contribute, we have to make a difference from what we have learned, to our community." This desire to make a difference was inherent in students' commentaries and each participant reflected on the selfdevelopment they were experiencing as a means of achieving this. They talked about the ways they were growing on a personal level.

\section{Theme 2: Self-Development}

This was the largest theme to emerge from the data, consisting of several elements. Students spoke about how their academic skills had improved, including their ability to be critical thinkers. They talked about how they had developed personally, sharing some of the insights they had acquired. They also talked about the challenges they had experienced and how their resilience had developed in response to these.

2a: Academic Skill Development. Students reflected on how their academic skills had matured, including literature searching, reading, writing and the ability to think critically. They referred to the discipline required in academic writing, and the need for accuracy, justification, and support of any discussion with evidence and references. The improvement in academic writing was based on improved skills in literature searching which enabled them to find evidence to support their work. The students recognized the programme was cultivating their critical thinking skills and that this was a central element threaded throughout the programme. One student explained: "I was thinking that any written, published article or any research I was considering was true. . . but nowadays I have to see critically ... yes that was the most important thing." The student continues with how this had impacted positively on his work:

I can see now there was a very big gap at the time compared to this. I was not really able to identify the types of the research and the methodologies and what data is. How to see from the finest point of view these things. Now I am able to manage these things in my job.

These findings demonstrate that e-learning programmes can be designed to cultivate the higher order cognitive skills that underpin advanced clinical practice. Students had become more discerning and questioning-the basis of evidence-based practice and a central tenet of clinical practice. They had gained an understanding of the need for critical awareness and were developing the ability to think critically and analytically.

Students explained their interpretation of critical thinking in terms of being able to see things from different perspectives and the need to consider alternative viewpoints. Also the importance of evaluating and synthesizing a range of evidence to support effective decision-making:

I just want to have the correct evidence in daily activities. . . if somebody is talking, joking sometimes telling me something. . . I want to have more like clarification, more evidence. It really has [an] impact as it's evidence based practice. . . like to have the evidences. . . to see things critically. It really has impacted in our daily life. 
2b: Personal Self-Development. Students discussed how they had grown on a personal level. Online learning at the master's level was challenging, but they could feel themselves growing and changing:

being a student is not joyful-actually it's stressful, but the end matters and when I see myself before I start the course and now and maybe after I finish my dissertation, there is a big difference and that difference is what I enjoy.

This change included the benefits they could bring to their communities: "Also giving help to the community with a new skill gives me satisfaction, not only for yourself, helping the community also gives me satisfaction.”

Students saw the programme as a means of developing themselves, so that in turn they could contribute to the ongoing development of their country. Students aspired to have this positive impact and some of them spoke of it as a moral obligation. The personal self-development students had experienced was in part a result of the challenges they had faced and how they had overcome these.

2c. Responding to challenges and resilience building. As well as discussing challenges and difficulties they had encountered, students talked of ways in which they had overcome these, finding solutions to the problems they faced, becoming resilient, so that what were previously regarded as challenges, became normalized. Acquiring these problem-solving skills was an important element of their self-development. For example, the student-centred approach employed in e-learning meant they had to improve their time management skills:

as time goes by you become highly skilled in the management of your time. In the first, maybe in the first two modules, it is a panic. . . because its strange and you have to read critically, so strange you are out of your comfort zone so the challenges present. . . Nowadays we have done many modules we have consolidated a lot... [so] that challenge by itself is becoming normal practice.

The transition from a traditional faf programme to distance learning was difficult for some students: completely different to their undergraduate experiences. Transitioning from a teacher-centred, didactic style, with students playing a passive learning role, to a student-centred experience requiring them to be active and autonomous learners was not easy:

in the undergraduate one you are dependent on your instructor for knowledge. Whereas in here we are dependent on our instructors for guidance. . . [and it is] a big, big difference. We don't expecting [sic] them to give out the entire knowledge. Whereas [in] undergrad [studies] the instructor taught us and [fed us] all the information and we can receive it-that's it. .. that is a big difference

Students understood the need to be independent learners and found the lack of internet connectivity and power cuts frustrating. As with other African countries there are rural and urban inequalities in internet access. Students in Asmara (Eritrea's capital) had better connectivity, whereas students in remote areas had intermittent internet access, experiencing periods of time when they were unable to go online. These students had to use local internet cafes which were expensive and not conducive environments in which to study. Students often had to resort to travelling long distances into Asmara to get internet access. 
Students also spoke of the frustration when having managed to get online, they could not access particular websites, or had to pay for this. Students found the online University library system difficult to access, having to navigate through several links before reaching the page they wanted, by which time they had often lost the connection. However, students had developed strategies for overcoming these connectivity issues. Some students had transferred to posts in Asmara. Others asked fellow students to help with accessing information and students based in the city acted as mediators for those in remote areas, relaying information from the University:

we solved the issue by just for example ... the students who are here they helped the other students just in downloading the information required. Some of the students they help and the students they know us they are the people who are here in Asmara.

Some students had accessed organizations in Asmara with more reliable internet connections, using their professional and personal networks to use these. Students acknowledged the importance of support from their bosses and the in-country visits by teaching staff, which they viewed as an opportunity to engage with teaching staff and as a means of peer support.

Students had built networks of mutual support, which mitigated against some of the challenges they experienced. This sense of community and mutual support operates at a number of levels. There is the sense of student community as they help and support each other in their studies. Then there is the sense of community in terms of wanting to make a contribution to their country. Finally, there is the sense of community in being Eritrean, proud of having won their independence as a country.

This self-development helped students become more self-assured. They recognized they were growing and expanding their skills and knowledge as they became mature master's students. They were becoming more confident and assertive in their interactions with others.

\section{Theme 3: Building Confidence}

Students discussed how their confidence was increasing as they became more discerning readers, thinkers, and writers. They were aware that their thinking was different and they were becoming more self-assured in using and applying the academic skills they were developing: "most of the time reading some papers we simply, we don't see what happened, we can't comment. Now I am confident enough in the areas you have taught, I can comment and I can critique because of them."

They were also becoming confident in applying these skills to their daily practice to question the status quo. This was primarily with work colleagues as they began to ask why things were done in a particular way-where was the evidence to support colleagues' actions. Students were also becoming confident in sharing their new knowledge and ways of thinking with others, encouraging colleagues to think differently about how they practiced: "One thing that I have done differently. . . in practice I started to share cases to the colleagues, and the different professions, social workers, psychologists and also to similar positions to discuss about certain cases and giving time to my clients." This theme of confidence building was intertwined with that of influencing others and having an impact.

\section{Theme 4: Influencing Others and Having an Impact}

As students became more confident in sharing their knowledge, voicing opinions and speaking out, they were becoming more visible to others, particularly their superiors: 
now I know what programme is feasible. . . I can bring it to my boss to discuss. . . now I am pushing this to my boss. . I know what is better and I can explain it in front of the minister with the evidence base.

Their participation on the programme gave them credibility, their views were listened to, and they felt they were able to make a tangible contribution to changing the way in which services were planned and provided. One student explained: "we are confident enough to speak loudly, differently about these challenging problems." One student explained how they were now authorized to run their own research projects:

Before. .. whenever we want to develop research, the strategy, or the protocols we were hiring a consultant. Since last year we are trying to do it by ourselves with my colleagues. . . so we have changed a lot. We are going to do the research that is important for ourselves.... We are encouraged enough to start the work.

However, they acknowledged the need to work hard, demonstrating their potential and proving their credibility. They recognized the importance of being assertive, speaking out, and not being silent and they felt the skills they had acquired while being on the programme gave them the self-assurance to do this. Students saw their new knowledge and skills as a way to make a difference to their communityand they were keen to do this.

The theme of influencing others and having an impact links back to the initial Eritrean context theme as students felt their input would contribute to changing this context while they helped to develop the research base and improve the health system. They strongly believed they could play an important part in enabling Eritrea to continue developing and again expressed a moral obligation to play their part in achieving this. They were keen to take their learning and embed it into practice, supporting and developing their communities of practice.

\section{Discussion}

Delivering master's level e-learning programmes in Eritrea has been challenging due to unreliable internet connectivity and intermittent power cuts. Similar issues are reported across Africa (Boitshwarelo, 2009; Breetzke, 2007; Mtebe \& Raisamo, 2014; Rye \& Stokken, 2012; Wright, Dhanarajan, \& Reju, 2009). The growing divide between rural and urban areas (Gulati, 2008; Nyerere, Gravenir, \& Mse, 2012; Oladokun \& Aina, 2011) and the cost and inconvenience of having to use internet cafes is also documented (Andersson \& Gronlund, 2009; Letseka \& Pitsoe, 2014; Rye \& Stokken, 2012) and reflected in the views of Eritrean students based in rural areas.

What is interesting is how students overcame these issues to a certain extent, finding their own solutions to staying connected to each other, providing mutual support and alternative solutions to engage with programme materials. What is striking is the sense of cohesion and group identity that has developed. Distance and e-learning can be a lonely experience for individuals (Andersson \& Gronlund, 2009; Ojo \& Olakulehin, 2006; Wright et al., 2009). This study demonstrates that where student peer support develops, a sense of commonality and community can offset this isolation. 
Bernard et al. (2009) in a systematic meta-analysis of 74 research articles exploring online education concluded that while student-student, student-teacher and student-content interactions are all important in promoting learning, student-student interaction has the most positive effect. In addition to the carefully constructed opportunities for interaction designed by the programme team, students developed their own methods of interaction to promote learning among themselves and with a wider audience of work colleagues. However, it is recognized that this cohort of Eritrean students and their situation is perhaps unique. The ability to support e-learning elements of the programme with incountry f2f teaching visits has been critical in bringing students together to initiative peer support, develop relationships with teaching staff and ensure students have essential learning materials, regardless of internet and power connections.

Balanced against these challenges, advantages cited by students included being able to fit their studies around other commitments, both social and work-related. Rye and Stokken (2012) discuss the importance of educators being aware how students' local context can impact on their engagement with distance education and the need to consider their "daily social world" (p. 192). Effective time management is highlighted in the literature as an important consideration for distance learners (Broadbent \& Poon, 2015; Wright et al., 2009); also, the need for a strong locus of internal control to maintain student-centred learning (Hamdan, 2014; Marginson, 2014). This was reflected by the Eritrean students who, while appreciating the flexibility afforded by the programme, acknowledged the need for discipline and time management skills.

The study has demonstrated higher order cognitive skills such as critical thinking, analysis, and evaluation can be successfully developed via an e-learning programme. The views of students are endorsed by the fact they have progressed successfully through the taught elements of the programme, demonstrating the ability to achieve learning outcomes at master's level. There is debate regarding whether imposing this westernized approach to education requiring a readiness to engage in critical discussion and a questioning approach is appropriate for students used to more passive learning roles and where such questioning may be regarded as disrespectful (Andersson \& Gronlund, 2009; Eaves, 2011; Rye \& Stokken, 2012). Pyvis \& Chapman (2005), Rye \& Stokken (2012) and Zhou, Jindal-Snape, Topping, \& Todman (2008) discuss the culture shock these students experience. Eritrean students certainly found the student-centred, active-learning philosophy different to their previous experiences. However, the results demonstrate they have embraced this approach, seeing the benefits it brings to their studies, the way they develop confidence and self-assurance in interacting with their colleagues and the positive impact on practice. Saito (2003) discusses Amartya Sen's capability approach to human development and well-being, quoting Sen's argument that education increases human capability: "This can be through a person benefitting from education 'in reading, communicating, arguing and being able to choose in a more informed way, in being taken more seriously by others and so on'” (p.24)

These attributes were clearly articulated by the Eritrean students who spoke of becoming more visible and listened to by others and of the way in which their contribution was valued by their colleagues and superiors-they felt they were being taken seriously.

\section{Conclusion}

This study exploring the experiences of Eritrean health care students undertaking postgraduate distance learning programmes has demonstrated that higher order cognitive skills, such as critical 
thinking and analysis, can be successfully cultivated using a blended distance learning model. While elearning is challenging for these students due to limited connectivity and internet access, students developed resilience in surmounting these difficulties. The additional support provided by regular incountry teaching visits is also critical. In addition to developing academic skills, students engaged in a process of self-development and confidence building, which they perceived as beneficial in being able to have a positive impact on the delivery and development of health services. The skills these students have developed will have a lasting impact long after they have completed their studies.

This is a small scale study however, and these distance learning students are unusual in terms of being geographically connected and able to interact physically with each other and the teaching team on a regular basis via the blended learning approach. Further investigation into this type of online delivery, supported by in-country teaching visits, is needed from both students' and teaching staff perspective. The research team are currently conducting studies with another cohort of students based in Kenya to compare findings with the Eritrean cohort and also the experiences of staff who regularly travel to both countries to teach these students. In addition, the in-country teaching visits appear to be a crucial element in supporting students and it would be interesting to compare completion rates of this type of blended delivery with those of an online delivery only.

\section{References}

Andersson, A. \& Gronlund, A. (2009). A conceptual framework for e-learning in developing countries: a critical review of research challenges. Electronic Journal on Information Systems in Developing Countries, 38(8), 1-16.

Bernard, R. M., Abrami, P.C., Borokhovski, E., Wade, C. A., Tamim, R. M., Surkes, M. A., \& Bethel, E. C. (2009). A meta-analysis of three types of interaction treatments in distance education. Review of Educational Research, 79(3), 1243-1289.

Boitshwarelo, B. (2009). Exploring blended learning for science teacher professional development in an African context. The International Review of Research in Open and Distance Learning, $10(4), 10-19$.

Breetzke, G. D. (2007). A critique of distance learning as an educational tool for GIS in South Africa. Journal of Geography in Higher Education, 31(1), 197-209.

Broadbent, J. \& Poon, W. L. (2015). Self-regulated learning strategies \& academic achievement in online higher education learning environments: a systematic review. Internet and Higher Education 27, 1-13.

Eaves, M. (2011). The relevance of learning styles for international pedagogy in higher education. Teachers and Teaching: Theory and Practice, 17(6), 677-691.

Gerrish, K., \& Lacey, A. (2010). The research process in nursing (6th ed.). Oxford: Wiley-Blackwell. 
Gravani, M.N., \& Karagiorgi, Y. (2014). Underpinning principles in adult learning in face to face (f2f) meetings employed by distance-teaching universities. Journal of Adult \& Continuing Education, 20(1), 53-67.

Gulati, S. (2008). Technology-enhanced learning in developing nations: a review. The International Review of Research in Open and Distance Learning, 9(1), 1-16.

Hamdan, A. (2014). The reciprocal and correlational relationship between learning culture and online learning: a case study from Saudi Arabia. The International Review of Research in Open and Distance Learning, 15(1), 309-336

Knowles, M. (1990). The adult learner: a neglected species (4th ed.). Gulf Publishing, Houston.

Letseka, M., \& Pitsoe, V. (2014). The challenges and prospects of access to higher education at UNISA. Studies in Higher Education, 39(10), 1942 - 1954.

Marginson, S. (2014). Student self-formation in international education. Journal of Studies in International Education, 18(1), 6-22.

Mtebe, J., \& Raisamo, R. (2014). Investigating perceived barriers to the use of open educational resources in higher education in Tanzania. The International Review of Research in Open and Distance Learning, 15(2), 43-66.

Nyerere, J. K. A., Gravenir, F. Q., \& Mse, G. (2012). Delivery of open, distance and e-learning in Kenya. The International Review of Research in Open and Distance Learning, 13(3), 185-204.

Ojo, D. O., \& Olakulehin, F. K. (2006). Attitudes and perceptions of students to open and distance learning in Nigeria. The International Review of Research in Open and Distance Learning, 7 (1), 1-10.

Oladokun, O., \& Aina, L. (2011). ODL and the impact of digital divide on information access in Botswana. The International Review of Research in Open and Distance Learning, 12(6), 157177.

Pyvis, D., \& Chapman, A. (2005). Culture shock and the international student "offshore." Journal of Research in International Education, 4(1), 23-42.

Rye, S. A., \& Stokken, A. M. (2012). The implications of the local context in global online education. The International Review of Research in Open and Distance Learning, 13(1), 191-206.

Saito, M. (2003). Amartya Sen's capability approach to education: a critical exploration. Journal of Philosophy of Education, 37(1), 17-33.

Shams, F. \& Huisman, J. (2012). Managing offshore branch campuses: an analytic framework for institutional strategies. Journal of Studies in International Education, 16(2), 106-127.

UN. (2014). Eritrea. Delivering together for Eritrea's development and self-reliance. United Nations Eritrea. Retrieved from www.afro.who.int/index.php?option=com docman\&task 
van Zyl, J. M., Els, C. J., \& Blignaut, A. S. (2013).Development of ODL in a newly industrialized country according to face-to-face contact, ICT and E-READINESS. The International Review of Research in Open and Distance Learning, 14(1), 84-194.

Vygotsky, L. S. (1978). Mind in society. Cambridge MA: MIT Press.

WHO. (2014). WHO country cooperation strategy 2014-2016 Eritrea. Regional Office for Africa. Retrieved from http://www.who.int/iris/handle/10665/148539

World Bank (2000). Eritrea-Country assistance strategy: interim support strategy. Retrieved from http://documents.worldbank.org/curated/en/891491468236074710/Eritrea-Countryassistance-strategy-interim-support-strategy

World Bank. (2015). Retrieved from http://www.worldbank.org/en/country/eritrea/overview

Wright, C., Dhanarajan, G., \& Reju, S. (2009). Recurring issues encountered by distance educators in developing and emerging nations. The International Review of Research in Open and Distance Learning. 1O(1), 1-25.

Zhou, Y., Jindal-Snape, D., Topping, K., \& Todman, J. (2008).Theoretical models of culture shock and adaptation in international students in higher education. Studies in Higher Education, 33(1), $63-75$.

\section{Athabasca University}

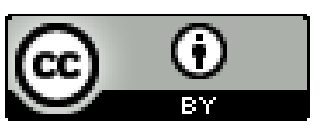

